\title{
Prenatal Diagnosis of Cross-fused Renal Ectopia: Still a Dilemma
}

\author{
${ }^{1}$ Shraddha Singhania, ${ }^{2}$ Akhita Singhania, ${ }^{3}$ Saherish Khan, ${ }^{4}$ Vaibhav Kumar, ${ }^{5}$ Pooja Singhania
}

\begin{abstract}
Cross-fused renal ectopia (CRE) is a rare congenital anomaly where during development of the fetus, one kidney migrates to the opposite side and fuses with the kidney of that side. Crossfused ectopic kidney with contralateral pelvic kidney is a rare finding. Proper knowledge of morphological variations of kidneys is essential to avoid postnatal renal dysfunction and morbidity.
\end{abstract}

Keywords: Antenatal, Cross-fused kidney, Ectopia, Pelvic kidney.

How to cite this article: Singhania S, Singhania A, Khan S, Kumar V, Singhania P. Prenatal Diagnosis of Cross-fused Renal Ectopia: Still a Dilemma. Donald School J Ultrasound Obstet Gynecol 2017;11(3):225-226.

\section{Source of support: Nil}

Conflict of interest: None

\section{INTRODUCTION}

Routine prenatal sonography is performed in prenatal care to screen for fetal anomalies. Severe structural fetal anomalies affect approximately $1 \%$ of pregnancies, and $20 \%$ of these involve the genitourinary system. ${ }^{1}$ The kidneys are routinely evaluated on second- and thirdtrimester obstetric sonographic examinations of the fetus. Failure to identify a kidney in the fetal renal fossa on prenatal sonography may be due to technical factors, such as fetal position or maternal body habitus, or it may be due to the fact that the kidney is not there. Cross-fused renal ectopia is the fusion of both kidneys, with at least one kidney on the side opposite of its normal location. But the ureter of the ectopic kidney crosses the midline following the normal course to open in its normal position in the urinary bladder. Cross-fused renal ectopia is one

\footnotetext{
1,4,5Consultant, ${ }^{2,3}$ Junior Resident

${ }^{1-3}$ Department of Radiodiagnosis, Jawaharlal Nehru Medical College, Wardha, Maharashtra, India

${ }^{4}$ Department of Radiology, Narinder Mohan Hospital and Heart Centre, Ghaziabad, Uttar Pradesh, India

${ }^{5}$ Ahimsa Dham Bhagwan Mahavir Medical Centre, Patparganj New Delhi, India

Corresponding Author: Shraddha Singhania, Consultant Department of Radiodiagnosis, Jawaharlal Nehru Medical College, Wardha, Maharashtra, India, e-mail: drshraddha singhania@hotmail.com
}

of the rarest anomalies of urinary system. Cross-fused renal ectopia is the second most common fusion anomaly of the kidney with an incidence of 1 in 7,000 at autopsy, the first being horseshoe kidney. ${ }^{2}$ Most of the cases of CRE are asymptomatic and are diagnosed at autopsy, incidentally during radiological investigation or during cadaveric dissection. We report a case of a fetus initially suspected to have unilateral renal agenesis, which on further sonographic imaging with color Doppler imaging was diagnosed as CRE.

\section{CASE REPORT}

A 27-year-old primigravida presented to our department for routine fetal anatomic survey at 18 weeks of gestation. Her obstetric history this far had been normal. The antenatal sonography revealed an empty bilateral renal fossa. No other fetal anomalies were noted on the examination; however, the patient had oligohydramnios (amniotic fluid index 6); thus, a presumptive diagnosis of bilateral renal agenesis was made. Patient was followed up after 6 weeks. At 24-week gestation, a follow-up sonography continued to show an empty bilateral renal fossa; however, there appeared right kidney lying above the bladder in the pelvis and there was a cross-fused kidney attached to it (Fig. 1). On color Doppler imaging, there were separate vascular supplies from the aorta to the right kidney and to the cross-fused left kidney (Fig. 2). The findings confirmed the diagnosis of CRE.

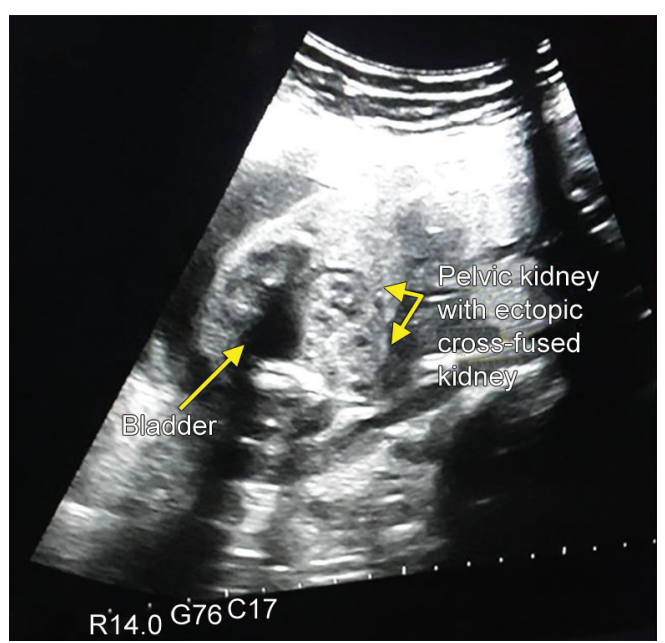

Fig. 1: Antenatal scan view of pelvic kidney with cross-fused ectopic kidney 


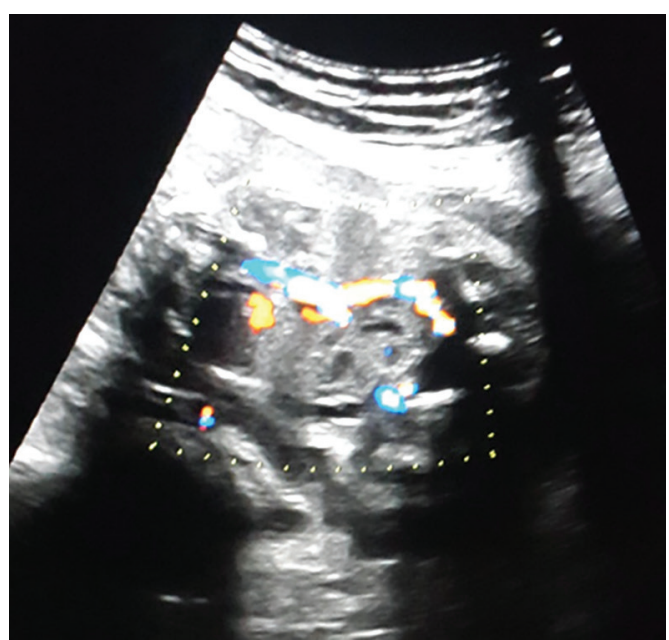

Fig. 2: Color Doppler having the ectopic kidneys with their vascular supply

\section{DISCUSSION}

Kidney starts developing by 4 th week of gestation by intercommunication between ureteric bud and nephrogenic cord in the pelvis at second sacral vertebra level. Initially, the hila of both kidneys face anteriorly and kidneys are placed close to each other. During 6th to 8th week of gestation, the fetal kidney ascends along the posterior abdominal wall to its normal position, i.e., in the lumbar region adjacent to the suprarenal gland which is still developing. While ascending, it undergoes 90 degrees axial rotation resulting in rotation of hilum medially.

There are two types of renal fusion anomalies:

1. Horseshoe kidney

2. Cross-fused renal ectopia

While ascending, if kidneys fuse in the midline, it forms horseshoe kidney and if one kidney's inferior pole fuses with superior pole of other kidney, it results in CRE. However, in our case, both the kidneys were ectopic as right kidney was in pelvis with superior pole of left kidney attached to inferior pole of right kidney. Other theories regarding the cause of CRE are abnormally placed umbilical arteries, malrotated caudal end of the fetus, teratogenic factors, or genetic factors. ${ }^{3,4}$
The process of ascending of the kidneys is completed by 10th week of gestation; hence, evaluation of kidneys can be done in later first trimester or early second trimester. But in our case, we were unable to diagnose the CRE until 24 weeks of gestation. In a study of 26 renal ectopia, Meizner et $\mathrm{al}^{3}$ noted that the gestational age at diagnosis was between 18.5 and 38 weeks and majority of the cases were diagnosed after 24 weeks of gestation despite prior ultrasonography. It has been reported in the literature that detection of pelvic kidney is confirmative during advanced gestational age or after 24 weeks of gestation. ${ }^{5,6}$ Developing renal anomalies can be due to pelvic kidneys with increase in risk of hydronephrosis.

\section{CONCLUSION}

Prenatal diagnosis of ectopic cross-fused kidneys is a difficult diagnosis for a radiologist when both the kidneys are absent from its normal position (renal fossa). When recognized, other associated congenital anomalies should be looked for in the fetus. If there are no other abnormalities, patients can be counseled about continuing the pregnancy and not worrying about the outcome of their child as the fetus after being born can have normal renal function. And early detection of renal anomaly can help in careful evaluation of the baby postnatally and can prevent unnecessary deaths associated with abnormal renal functions.

\section{REFERENCES}

1. Chow JS, Benson CB, Lebowitz RL. The clinical significance of an empty renal fossa on prenatal sonography. J Ultrasound Med 2005 Aug;24(8):1049-1054.

2. Patel TV, Singh AK. Crossed fused ectopia of the kidneys. Kidney Int 2008 Mar;73(5):662.

3. Meizner I, Yitzhak M, Levi A, Barki Y, Barnhard Y, Glezerman M. Fetal pelvic kidney: a challenge in prenatal diagnosis? Ultrasound Obstet Gynecol 1995 Jun;5(6):391-393.

4. Boyan N, Kubat H, Uzum A. Crossed renal ectopia with fusion: report of two patients. Clin Anat 2007 Aug;20(6):699-702.

5. King KL, Kofinas AD, Simon NV, Deardorff J. Prenatal diagnosis of fetal pelvic kidney. A case report. J Reprod Med 1993 Mar; 38(3):225-226 .

6. Colley N, Hooker J. Prenatal diagnosis of pelvic kidney. Prenat Diagn 1989 May;9(5):361-363. 